
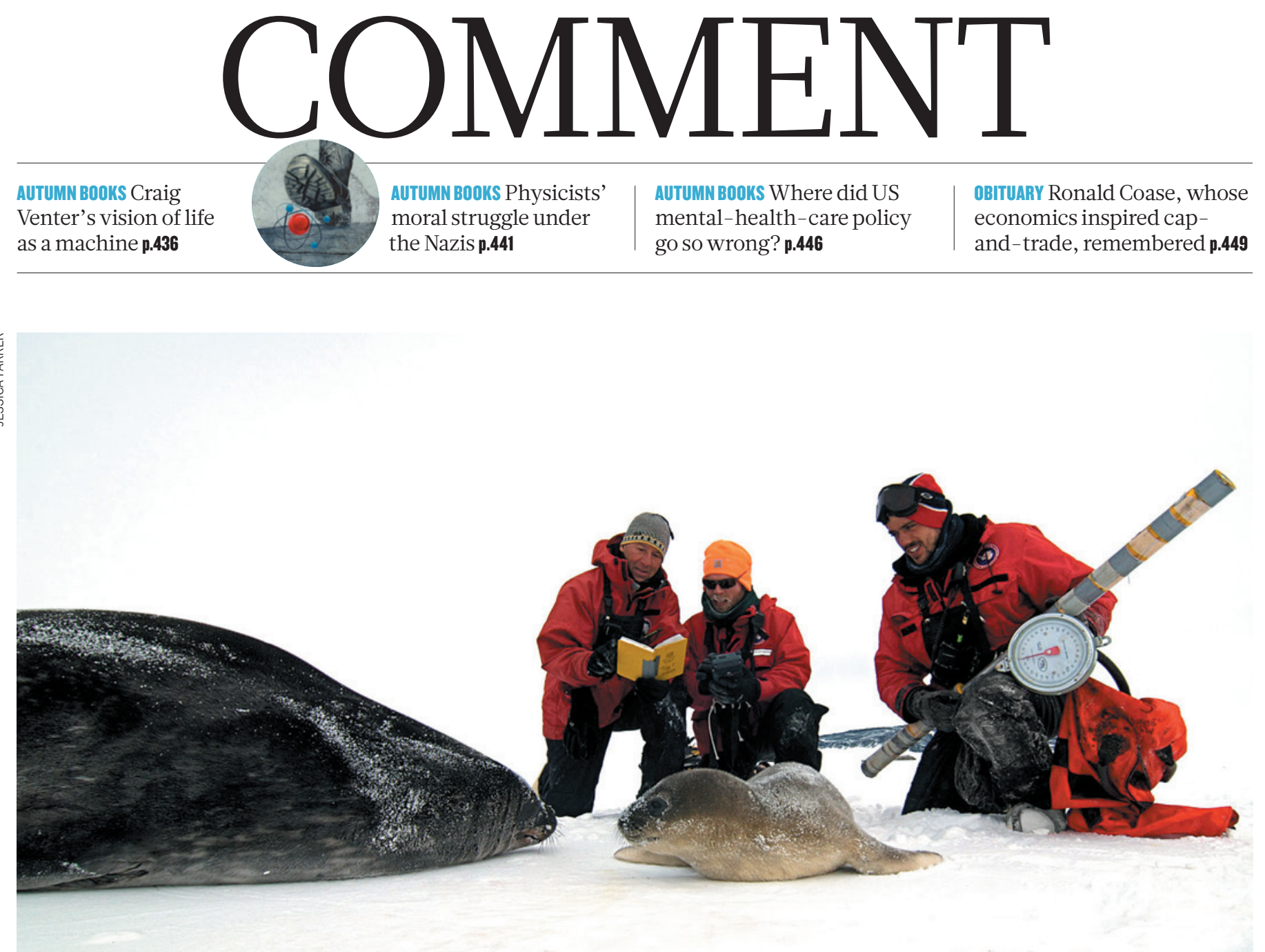

Ecologist Jay Rotella (left) collects data in Antarctica on Weddell seals, with his students Glenn Stauffer and Thierry Chambert (right) in 2010.

\title{
The long shadow of the shutdown
}

\section{Stalled Antarctic field work as a result of the US government shutdown has jeopardized early-career scientists and their projects, says Gretchen E. Hofmann.}

$\mathrm{F}$ Tor 13 seasons studying ocean-change biology in Antarctica, the familiar landmarks of Mount Erebus, Observation Hill and Castle Rock - visible even in a ground blizzard - have directed me back across the sea ice to the US research base, McMurdo Station. But when my postdoctoral researcher, Amanda Kelley, arrived on the sea ice of McMurdo Sound earlier this month, the direction of her research was not so clear.

As a polar research fellow, funded by the US National Science Foundation (NSF), Kelley was greeted with the news that her field season had been cancelled. On 1 October, the US federal government shut down after Congress failed to agree on a budget for the next fiscal year. One week later, the ensuing lapse in funds for the US Antarctic Program (USAP; www.usap.gov) meant that McMurdo Station was switched to 'caretaker' status, meaning that activities focused solely on protecting personnel and property.

Even though a fiscal deal was reached in Washington DC on 16 October, ending this surreal shutdown, these few weeks of delay, of lost data and of instruments becoming ever more irretrievable, may have already irreparably damaged the season's research.
Furthermore, the current deal extends funding until only next January - before the end of the Antarctic research season. The consequences may be indelible, particularly for early-career scientists (see 'Out of season').

Projects on topics from ice-sheet dynamics to penguin ecology have been put at risk. Delaying work reduces the time that research in certain areas can be done; for example, soon, warmer weather will soften the sea ice and render it unsafe for travel.

I have a front-row seat to this stressful drama. The ocean-change biology research programme in McMurdo Sound that 
I lead has been suspended indefinitely because of the shutdown. Kelley has gone to New Zealand and hopes to return later to McMurdo; the deployment to Antarctica of my graduate student, Lydia Kapsenberg, has been delayed indefinitely until further notice.

\section{AGAINST THE CLOCK}

Both these researchers' projects are timesensitive. Kelley is examining responses to ocean acidification and warming in earlystage Antarctic sea urchins. Because urchins produce eggs in October, she needs to collect specimens immediately. In the first year of a two-year fellowship, her stipend will run out before her project is completed because of the delay.

Kapsenberg's research on ocean acidification requires $\mathrm{pH}$ measurements of Antarctic waters ${ }^{1}$. Last November, we deployed an autonomous oceanographic sensor called a SeaFET $^{2,3}$ at Cape Evans. That sensor, now bobbing under the sea ice just off shore from explorer Robert Falcon Scott's historic hut, holds the first winter data that we have ever recorded at our site. If we are unable to reach it before the sea ice melts, we will lose the data and perhaps, by next year, the sensor too.

Other McMurdo-based projects could be crippled if the research season cannot be resumed. Samantha Hansen, a geologist at the University of Alabama in Tuscaloosa, who is funded by a prestigious NSF CAREER award, needs to recover data from and service 15 instrumented stations installed last season to record global earthquakes and study the Transantarctic Mountains ${ }^{4}$. Costing tens of thousands of dollars each, the stations risk becoming non-functional or permanently buried beneath deep snow in the coming year if they are not maintained. Such a loss would affect her two graduate students, her Korean collaborators, and her linked NSF-sponsored education and outreach efforts.

Seal biologist Jay Rotella at Montana State University in Bozeman stands to lose more than most. His team has been counting and tagging Weddell seal pups in the McMurdo Sound area every year since 1968 (ref. 5). "If we miss this year," Rotella told me, "we will break the 31-year string of knowing every

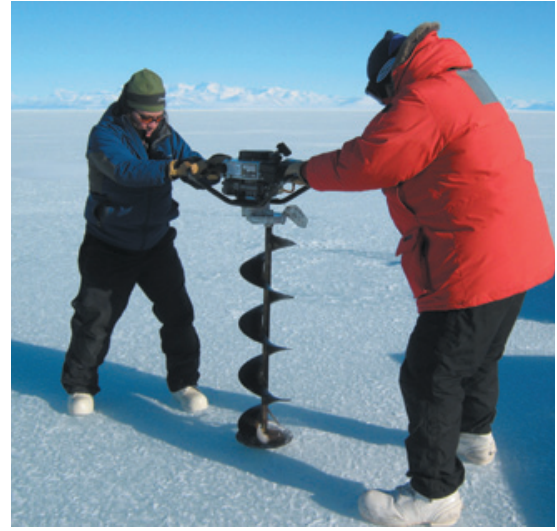

Ecologists Gretchen Hofmann (left) and Paul Matson collect water samples in Antarctica.

pup that is born in the population and of recording complete reproductive histories for thousands of mothers." This, as bad luck would have it, is also the year that the current crew leader, $\mathrm{PhD}$ student Thierry Chambert, is scheduled to train his successor. Such handovers are crucial for the continuity of the project, which has trained generations of scientists.

Anne Todgham of San Francisco State University in California is the only project leader whose whole team made it to McMurdo Station before travel to Antarctica was cancelled by the shutdown. They will begin a new project to investigate the vulnerability of Antarctic fishes to climate change. "Time is of the essence," she wrote in an e-mail to me. "October is our window to collect eggs and juveniles." The early developmental stages of fishes are predicted to be the most affected by climate change ${ }^{6}$. And, as Todgham puts it: "Unfortunately, climate change does not stop for a government shutdown."

\section{PERMANENT SCAR}

Long-term data sets, many of which form foundations for studying climate change, stand to suffer serious damage. The NSFfunded McMurdo Long Term Ecological Research (LTER) group, for example, which has been monitoring ecosystems in the McMurdo Dry Valleys since 1993, could be put in jeopardy ${ }^{7}$. Because the lakes found in the valleys are terminal - nothing flows out of them - they are sentinels to climate

\section{OUT OF SEASON}

The work of about a hundred US Antarctic Program personnel will be hindered by the suspension of the 2013-2014 field season due to the US government shutdown. More than half are early-career scientists.

\begin{tabular}{rrrr} 
Principal investigators & Postdocs & Undergraduate students \\
$22(\mathbf{2 0} \%)$ & $10(9 \%)$ & $3(3 \%)$ \\
\hline & & & \\
Early-career & Graduate students & International collaborators & Other* \\
principal investigators & $49(45 \%)$ & $3(3 \%)$ & $17(16 \%)$ \\
$5(4 \%)$ & &
\end{tabular}

change. A lost season of water-column and sediment data could "compromise exponentially" our knowledge of how polar systems respond to climate change, says John Priscu, a microbiologist at Montana State University.

The shutdown means "a huge step backward in educating the next generation of polar scientists, and straying from the spirit of international collaboration that has been at the centre of Antarctic research," Priscu says. This year, he had hoped to work at McMurdo with a recent graduate from the Chinese Academy of Sciences.

Diana Wall, a soil ecologist from Colorado State University in Fort Collins, examines soil invertebrates such as the roundworm Scottnema lindsayae, considered the "toughest invertebrate in the Valleys" ${ }^{\text {. }}$. Its numbers have declined at McMurdo, affecting carbon turnover in Antarctic soil. She knows that gaps in records will cause problems for years to come. "I am really sad to think of the missing data and how hard it will be for the students, postdocs and me to explain any changes we miss."

With the end of the shutdown, there is now a possibility that some research at McMurdo could go ahead, assuming that logistical arrangements are still in place to support scientists. Todgham's team could still accomplish a great deal, and Rotella's group could tag this year's batch of seal pups if the sea ice remains open. Hansen's geologists, set to deploy in early November, might be able to retrieve their instruments. And the McMurdo LTER group could yet preserve this year's contribution to their time-series data. We are all crossing our fingers.

But the shutdown and its consequences are likely to leave a permanent scar on junior scientists, including my own, as thesis projects remain in jeopardy because it is yet unclear whether research will resume. Postdocs may eventually leave Antarctic science because the risks are too high to be borne by untenured researchers. Meanwhile, as principal investigators, we wait to hear the fate of our Antarctic research.

Gretchen E. Hofmann is professor of marine biology at the University of California, Santa Barbara, 93016 USA. e-mail:hofmann@lifesci.ucsb.edu

1. Hofmann, G. E., Blanchette, C. A., Rivest, E. B. \& Kapsenberg, L. Oceanography 26, 140-148 (2013).

2. Hofmann, G. E. et al. PloS ONE 6, e28983 (2011).

3. Martz, T. R., Connery, J. G. \& Johnson, K. S. Limnol. Oceanogr. Methods 8, 172-184 (2010).

4. Hansen, S. E. et al. Geochem. Geophys. Geosyst. 10, Q08014 (2009).

5. Chambert, T., Rotella, J. J. \& Garrott, R. A. Proc. R. Soc. B 279, 4532-4541 (2012).

6. Munday, P. L., McCormick, M. I. \& Nilsson, G. E. J. Exp. Biol. 215, 3865-3873 (2012).

7. Doran, P. T. et al. Nature 415, 517-520 (2002).

8. Barrett, J. E., Virginia, R. A., Wall, D. H. \& Adams, B. J. Glob. Change Biol. 14, 1734-1744 (2008). 